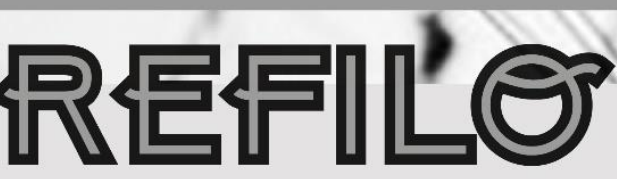

REVISTA DIGITAL DE ENSINO DE FLLOSOFIA

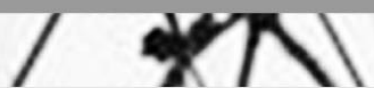

$x$

UNIVERSIDADE FEDERAL DE SANTA MARIA/UFSM SANTA MARIA, RS, BRASIL I ISSN 2448-0857

PERIODICOS.UFSM.BR/REFILO | FACEBOOK.COM/REVISTAREFILO | REFILOREVISTA@GMALLCOM I
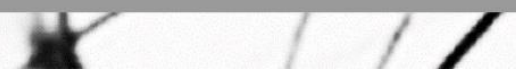

D

\title{
RESENHA DE/ REVIEW OF
}

\section{SERRES, MICHEL. POLEGARZINHA: UMA NOVA FORMA DE VIVER EM HARMONIA, DE PENSAR AS INSTITUIÇÕES, DE SER E DE SABER. RIO DE JANEIRO: BERTRAND BRASIL, 2015. $2^{a}$ EDIÇÃO.}

\author{
Gilberto Oliari1 \\ Jessica Erd Ribas ${ }^{2}$ \\ Raquel Brum Sturza ${ }^{3}$
}

Michel Serres, filósofo francês, constrói seu pensamento fora das "autoestradas". Nascido em 1930, habilitou-se em Matemática e em Filosofia, foi orientando de Gaston Bachelard e atuou em universidade francesa juntamente com Michel Foucault. A presente obra está dividida em três capítulos. De modo peculiar, Serres (2015) nos faz pensar sobre quem são os sujeitos que estão no processo educacional na era das tecnologias de informação e comunicação. $O$ próprio título Polegarzinha já remete a pensar sobre os(as) jovens que, com seus polegares, dominam as tecnologias na palma da mão. O autor revela que a construção do texto acontece a partir da convivência com seus netos e da análise de seu papel enquanto professor. De forma muito consciente, apresenta uma reflexão sobre o passado e o presente do processo educacional e, criativamente, desafia para uma construção reflexiva sobre o futuro da educação.

\footnotetext{
1 Graduado em Filosofia e Ciências da Religião - UNOCHAPECÓ; Especialista em História Regional - UFFS; Especialista em Ensino de Filosofia - UFSCAR; Mestre em Educação UNOCHAPECÓ; Doutorando em Educação - UFSM. E-mail: <gilba@unochapeco.edu.br>

2 Graduação em Licenciatura em Filosofia pela UFSM (2017) Mestranda em Educação PPGE - UFSM. E-mail: <erd.jessica@gmail.com>.

3 Mestranda em Educação (UFSM); Especialista em Gestão Educacional pela UFSM (2016); licenciada em Filosofia - UFSM (2014). E-mail: <raquelsturza@hotmail.com>
} 
Em uma escrita livre, que possibilita uma leitura tranquila e fácil, o autor destaca alguns elementos na tessitura do texto que podem ser sintetizados através dos conceitos de: suspensão do espaço geográfico; ruptura do tempo linear; formação humana como espiral. A resenha que segue busca analisar a obra a partir desses três eixos. Dessa forma, busca-se trazer, para discussão, afirmações contundentes produzidas pelo autor, bem como apresentar possíveis relações entre o que o texto defende e o Ensino de Filosofia no Ensino Médio.

Logo nas primeiras páginas da obra, Serres (2015) avisa que os sujeitos de sua reflexão "não habitam mais a mesma Terra, não têm mais a mesma relação com o mundo" (p. 13): para esses e essas, polegarzinhas e polegarzinhos, habitar o mundo significa fazer turismo e ter espaços de lazer. Nesse sentido, vive-se uma profunda mudança. Os antepassados desses jovens viviam em um local que, talvez por gerações, pertenceu à família; hoje, graças à globalização, pode-se dizer que o mundo é o local de habitação das gerações mais atuais. Estes que "não habitam mais o mesmo espaço" (SERRES, 2015, p. 19), por GPS têm acesso a todos os lugares e "circulam, então, por um espaço topológico de aproximações" (SERES, 2015, p.19), vivem em um não espaço, vivem no topo.

Essa mudança espacial provoca uma reflexão contundente sobre o espaço de aprendizagem. Outrora, o conhecimento concentrava-se em um lugar: em livros, dicionários, compêndios, enciclopédias, na escola, na sala de aula, na biblioteca. Na atualidade, "todo esse saber, essas referências, esses textos, esses dicionários se encontram [...] distribuídos por todo lugar, na sua própria casa" (SERRES, 2015, p. 26) ou seja, os espaços que eram frequentados para concentração e aprendizagem diluíram-se. O espaço agora é de proximidades imediatas e distributivas, pois "as novas tecnologias nos obrigam a sair do formato espacial inspirado pelo livro e pela página" (SERRES, 2015, p. 41), o espaço agora é virtual.

A máxima dessa discussão sobre alteração do espaço se dá na afirmação de que o "homo sapiens nunca parou de se mudar de um lado para o outro, tornando-se homo viator" (SERRES, 2015, p. 73). Segundo o autor, "as viagens se multiplicaram a ponto de transformar a percepção do ambiente em que se vive" (SERRES, 2015, P. 73). Nesse sentido, a pergunta "a qual comunidade você 
pertence?" é difícil de ser respondida, pois vive-se em uma malha mesclada, onde se cruzam e entrecruzam diversas pessoas, etnias, culturas, diversos textos e hiperlinks, de modo que cada qual tem a possibilidade de deixar suas marcas, suas impressões e seus modos de pensar o mundo. Embora haja uma admiração com essa diversidade de possibilidades, há tempo para contemplar tudo isso? Para pensar e ressignificar as experiências vistas e sentidas? Há tempo para ter tempo?

O tempo como condição de contemplação, de espanto e de assimilação é outro. "Não habitamos mais o mesmo tempo; eles vivem outra história" (SERRES, 2015, p. 17), eis o segundo eixo de análise das juventudes - um tempo não-linear. Hora de estudar, hora de dormir e horário para tudo está cada vez mais em desuso pelas gerações contemporâneas. O relógio mecânico, que por anos foi sendo aperfeiçoado, é deixado de lado; no lugar dele, um relógio digital, todo fluorescente, marca as horas, não mais através de um ponteiro com um lugar para ficar preso, e sim com marcações luminosas que criam inúmeras combinações de tempo, que rompem com a linearidade da história. Com a expectativa de vida beirando os oitenta e cinco anos, esses jovens terão muito tempo para optar por sair da casa dos pais, permanecer casados e aguardar herança e, sob cuidados paliativos, não terão morte dolorosa como outras gerações.

Não vamos pensar que o tempo mudou. As medidas de tempo continuam as mesmas, o que mudou foi a forma de perceber esse tempo. Parte dessa mudança de percepção acontece pelo avanço das tecnologias. Com esse avanço, os jovens "não conhecem, não integralizam nem sintetizam da mesma forma que nós, seus antepassados" (SERRES, 2015, p. 19). Esses jovens nasceram com hora marcada e, sob inúmeros avanços da medicina, não terão uma morte tão dolorosa, ou talvez, nem agonizarão numa cama de hospital esperando a morte. São sutis mudanças, que provocam grandes revoluções nos espaços onde habitam.

Todas essas transformações espaciais e temporais trazem consigo mudanças na forma de ensinar e aprender, pois, "outrora e recentemente, o saber tinha como suporte o corpo do erudito, do aedo, do contador de histórias" (SERRES, 2015, p. 25), dessa forma, bibliotecas vivas que sabiam muitas coisas eram o corpo docente. Contemporaneamente, o corpo docente é outro, a própria cabeça do estudante é outra. Serres (2015) se utiliza da história de São Daniel, que teve a cabeça 
decapitada pelo exército romano e mesmo assim continuou vivo na França, para afirmar que a polegarzinha "considera ter a própria cabeça nas mãos e à sua frente" (SERRES, 2015, p. 35), fazendo, dessa forma, uma alusão ao uso de computadores.

Segundo o pensador, "nossa cabeça foi lançada a nossa frente nessa caixa cognitiva objetivada" (SERRES, 2015, p. 36). Dessa forma, não se torna mais necessário memorizar muitos conhecimentos, porque, para acessá-los, basta utilizar um computador, ou até mesmo um celular, e ali estarão todas as informações, a um clique. Sendo assim, "de dentro da caixa (computador), o aprendizado nos permite a alegria incandescente de inventar" (SERRES, 2015, p. 36), ou seja, abre inúmeras possibilidades de relações, comparações, acesso a conhecimentos antes inimagináveis, que permitem criar ou reelaborar saberes. Sem dúvida, essas tecnologias desafiam o próprio professor a repensar suas práticas ao passo que não podemos negar, ou simplesmente ignorar, a presença nem tão silenciosa das tecnologias nas salas de aula, pois "as novas tecnologias nos obrigam a sair do formato espacial inspirado pelo livro e pela página" (SERRES, 2015, p. 41).

A atividade de pensamento também mudou, os estudantes atuais pensam de outra forma, eles pensam quando se distanciam de conhecimentos petrificados e com pouco sentido, quando se expressam, podem dizer que "penso e invento quando me distancio desse saber e, desse conhecimento, quando me afasto" (SERRES, 2015, p. 42). Aí há o aprendizado em espiral que não volta mais para o ponto de partida, está sempre disposto a se reinventar e a se repensar. As cabeças, fora do pescoço, convertem-se num vazio, em uma possibilidade de autonomia, vazio que representa a liberdade de pensar, de buscar em outras fontes e de conhecer a diversidade de argumentações existente, que permite a polegarzinha não se contentar apenas com aquilo que tem e a faz ir em busca de novidades.

Essas mudanças trazem consigo certa confusão para as gerações "mais experientes". Por isso Serres $(2015$, p. 53$)$ afirma que "a desordem tem razões que a própria razão desconhece". Essas desordens logo pretendem ser aprisionadas e formatadas, mas sempre encontram uma tangente, uma outra via para se revelar. O desafio é compreender que "a desordem, pelo contrário, areja, como em um aparelho que apresenta folga. E essa folga possibilita a invenção, a mesma que 
aparece entre o pescoço e a cabeça cortada fora" (SERRES, 2015, p. 53), ou seja, essa desordem, que se espalha, precisa desafiar e movimentar exercícios de pensamento para que ela seja compreendida e sejam tomados novos posicionamentos.

O autor faz ainda uma série de apontamentos que apresentam uma mudança na sociedade. Um dos aspectos discutidos é a questão do trabalho. A polegarzinha percebe um tédio no trabalho, ela não vê aspectos de sua identidade ou de sua formação serem respeitados, "espera se completar no trabalho. No entanto, não o consegue; no entanto, se entedia" (SERRES, 2015, p. 66). A realização pessoal e a felicidade, que outrora o trabalho trazia, já não é capaz de prender a atenção das novas gerações, o que acaba forçando uma transformação no mundo do trabalho.

O silêncio não é mais prerrogativa de atenção. Serres (2015) faz um elogio das vozes humanas, afirmando que "a palavra humana balburdia no espaço e no tempo" (p. 69), as salas e vilas silenciosas regidas pela escrita dão lugar ao falatório. Essa mudança é perceptível quando se analisam os espaços virtuais: todos querem se comunicar, gravar um áudio e encaminhar. É mais rápido do que escrever. "Todo mundo quer falar, todo mundo comunica com todo mundo, por redes inumeráveis" (SERES, 2015, p. 70), dessa forma, o som toma o lugar visual da leitura, provocando uma democratização do saber através dos inúmeros outros espaços possíveis de comunicação.

Ao findar a obra, Serres (2015) afirma que todo esse contexto desafia o passado a se repensar. Em suas palavras, "volátil, viva e suave, a sociedade de hoje mostra mil línguas de fogo ao monstro de ontem e de antigamente, duro, piramidal e gelado. Morto" (p. 94), ou seja, urge a necessidade de se repensar e de inventar novas formas de desenvolver o processo de ensino-aprendizagem. As novidades são inúmeras e, de certa forma, não sabemos como lidar com tudo isso. Daí a necessidade de pensar e estudar, talvez não como no passado, quando se demorava anos para encontrar uma resposta, mas fazendo e pensando, construindo e avaliando novas práticas.

Nesse sentido, com um texto bastante elucidativo e atual, Michel Serres oferece elementos que provocam a pensar também, sobre outros temas como por 
exemplo o ensino de Filosofia. Vejamos que o exercício filosófico exige espanto e admiração. Nós, "os mais velhos", nos admiramos com tantas rupturas espaçotemporais, mas, os jovens, que já nascem inseridos, têm dificuldade em perceber o quanto isso altera sua própria identidade. Ao admirar, conseguimos contemplar, pensar, estabelecer relações e dar sentido e significado a tudo isso, aí se insere parte do papel do Ensino de Filosofia, talvez precisemos encontrar meios para que o jovem contemple o seu estado, a sua realidade e pense sobre ela. Assim com a Filosofia, podemos ver nascer o novo.

Pode-se perceber ao longo da obra que o autor tem uma escrita clara e desafiadora, utiliza-se de argumentos simples para instigar a percepção e o pensamento sobre a mudança na forma de compreender os jovens que são os sujeitos do processo educacional. Podemos considerar que sua escrita é objetiva pois apresenta suas ideias sem rodeio e coerente, pois há um desencadeamento dos elementos que possibilita compreender toda sua argumentação. A leitura dessa obra é fundamental para professores em processo de formação inicial e/ou continuada que tem como objetivo entender melhor as juventudes da atualidade. 